\title{
Clinical and serological comparison of 17 chronic progressive systemic sclerosis (PSS) and 17 CREST syndrome patients matched for sex, age, and disease duration
}

\author{
DANIEL E. FURST, PHILIP J. CLEMENTS, MARWAN SAAB, \\ MILDRED G. STERZ, AND HAROLD E. PAULUS
}

From the Department of Medicine, UCLA Center for Health Services, Los Angeles, California, USA

SUMMARY This study compares the clinical and serological differences between 17 PSS and 17 carefully matched CREST patients. Patients were matched for sex, age by decade, and, importantly, disease duration $(11 \cdot 2 \pm 9 \cdot 2$ vs. $12 \cdot 0 \pm 9 \cdot 3$ years). Muscular and skin involvement were greater for the PSS groups $(\mathrm{p}<0 \cdot 02)$ and pulmonary involvement was also greater $(\mathrm{p}<0 \cdot 05)$, at least for non-smoking PSS patients. On the other hand no clinically significant differences were found between groups for other visceral involvement - including comparisons of gastrointestinal, cardiovascular, and renal involvement. There were also no laboratory differences except in anti-RNP antibody $(\mathrm{p}<0 \cdot 04)$.

Key words: PSS, CREST, clinical, serologies.

Progressive systemic sclerosis (PSS) is a systemic disease defined by hide-binding or tethering of the fingers and skin proximal to the metacarpalphalangeal joints (MCPs) ${ }^{1}$ and it may be associated with the CREST syndrome (subcutaneous calcinosis, Raynaud's phenomenon, oesophageal dysmotility, sclerodactyly, and telangectasia). Controversy exists as to whether the CREST syndrome is a separate entity from PSS and whether it implies a different severity of disease than PSS. ${ }^{2-7}$

We therefore undertook a case-controlled comparison of 17 CREST and 17 matched PSS patients to determine if PSS and CREST patients differ in the degree or prevalence of their internal organ involvement. Serological comparisons were also undertaken.

\section{Patients and methods}

CREST PATIENTS

All 17 CREST patients had at least three of the five cardinal signs of the CREST syndrome (Table 1).

Accepted for publication 4 July 1984 .

Correspondence to Daniel E. Furst, MD, Department of Internal Medicine, E440-F, University of Iowa Hospitals and Clinics, Iowa City, Iowa 52240, USA.
Eight patients met all five criteria: six patients met four criteria, and three patients met three criteria. Sclerotic skin involvement was limited to the fingers in the CREST syndrome patients. In fact, the presence or absence of the major criterion for PSS (i.e., proximal scleroderma) separated our groups. Further, no CREST syndrome patient had any other definable rheumatological disease. The presence or absence of visceral involvement was not considered when we selected the CREST syndrome population.

The patients in the CREST syndrome group were involved in prospective studies at UCLA or were followed after a complete comprehensive diagnostic examination. Although no CREST patient met the major criterion for PSS, 12 met minor criteria (Table 1). Seven had sclerodactyly and pitting scars (two also had fibrosis on chest $x$-ray), and five others had sclerodactyly and pulmonary fibrosis but no pitting scars. Five CREST patients did not meet criteria for PSS.

We screened over 150 prospectively followed up patients with systemic sclerosis and its variants to find 17 CREST syndrome patients as defined in this study. These 17 CREST patients were then matched to 17 PSS patients for sex, age, and disease duration. Further, perhaps because we are part of a tertiary 
care facility, we found few CREST syndrome patients with disease duration less than five years from the first symptom (Table 1).

\section{PSS PATIENTS}

The 17 PSS patients had sclerodactyly and also had sclerotic skin changes proximal to the MCP joints, thus satisfying the major ARA criterion for that disease $^{1}$ (Table 1).

The PSS patients (who were enrolled in prospective studies of PSS at UCLA), were matched to the CREST patients by sex (one male and 17 females in each group), age by decade (48.2 \pm 10.9 (SD) vs. $49.5 \pm 10.9$ years), and disease duration from first symptom $(11 \cdot 2 \pm 9 \cdot 2$ vs. $12 \cdot 0 \pm 9 \cdot 3$ years $)$. The first symptom was Raynaud's phenomenon in most cases.

\section{DIAGNOSTIC TESTS}

The studies done for evaluation of organ involvement included a history, a physical examination including a graded skin index, chest $x$-ray, electrocardiogram (ECG), treadmill, echocardiogram, cine oesophagogram with small bowel follow-through, barium enema, faecal fat determination, $x$-rays of the hands and feet, pulmonary function tests with spirometry, lung volumes, diffusing capacity and compliances, serum creatinine, serum creatine phosphokinase (CPK), electromyogram (EMG), and 24-hour urine for creatinine and protein.

Immunological tests included antinuclear antibody (ANA) using rat liver as substrate, latex fixation for rheumatoid factor, anti-ribonuclearprotein (RNP) and anti-Sm by haemagglutination, third component of complement (C3), antibody to single-stranded DNA (anti-ss-DNA), and quantitative immunoglobulins, all as routinely done in the UCLA Clinical Laboratories.

The organ systems tested included skin, kidneys, upper and lower gastrointestinal tract, joints, muscles, general cardiac, right heart, left heart, and pulmonary.

Several tests relating to any organ or organ system were done to define whether (and how much) that organ system was affected by disease (see Appendix A). For degree of involvement, objective tests or examinations were used whenever possible, and tests were weighted according to their estimated clinical importance. Frequently this approach resulted in conservative estimates of involvement. For example, muscular involvement was estimated by creatine phosphokinase and EMG, rather than adding some semiobjective measure of weakness such as muscle strength testing.

Pulmonary evaluation included symptomatic shortness of breath, fibrosis on chest radiograph, and diffusing capacity (Appendix A). Any degree of smoking affected all pulmonary function tests adversely, so smokers and non-smokers were analysed separately. Unfortunately this also meant that patients were no longer matched, and pulmonary evaluation required non-paired testing.

The skin index used in the above formulations is a semiquantitative method to assess skin 'hide-binding' or 'tethering', and involves palpation of the skin over 10 areas (face, back, chest, abdomen, arms, forearms, hands, thighs, legs, and feet). If the skin is not bound down or tethered, it is scored as $0 ; 1$ is minimal tethering; 2 is moderate tethering; and 3 is severe tethering. Twelve PSS patients, not specifically part of this study, were examined twice by the same investigator on two separate days within the same week, while seven patients were examined by two of the investigators on the same day. The intraindividual variation for the skin index was $8.5 \pm 9 \%$ with a coefficient of variation of 0.06 . The interindividual coefficient of variation for the skin index was $0 \cdot 08$. Agreement between the two investigators' skin indices was within 2 units out of a maximum possible index of $30(10 \pm 12 \%)$ at all times.

Statistical analyses employed Fisher's exact test for evaluation of the presence of disease (Table 2). Analysis of differences in degree of involvement employed Student's two-tailed matched $t$ test for all comparisons except pulmonary, where the twotailed unpaired $t$ test was used. Cardiac evaluation included a correction for repeated testing, for the ECG was used repeatedly in the general cardiac and left and right heart evaluations. Power analysis was done by the tables and methods outlined by Cohen. ${ }^{8}$

\section{Results}

The patient's characteristics are outlined above, and the similar ages and disease duration indicated that matching was quite good. Table 1 shows the number of CREST criteria found for each patient in both groups. In the CREST group 14 out of the 17 patients met at least four criteria. Twelve of the 17 patients with CREST had PSS also, all by minor criteria. This contrasts with the control group, all of whom had PSS by the major criterion. Table 2 summarises the concordance of organ involvement in the two patient populations. In the 10 systems evaluated no differences were noted except for muscular involvement $(p<0 \cdot 06)$. More PSS patients had myopathy, defined by CPK and EMG (see Appendix A), while none had myositis. Thus in terms of the presence of organ involvement there 


\begin{tabular}{|c|c|c|c|c|c|c|c|c|c|c|}
\hline Patient & Age/sex & 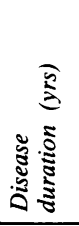 & 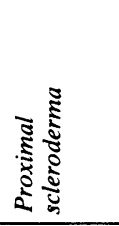 & 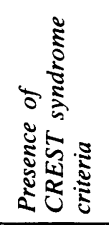 & 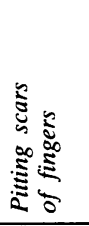 & 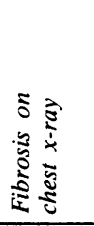 & 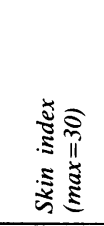 & 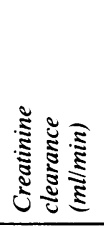 & 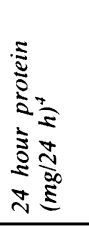 & 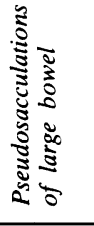 \\
\hline \multicolumn{11}{|l|}{ CREST } \\
\hline 1 & $54 / \mathrm{F}$ & 31 & 0 & CREST & + & + & 3 & 48 & 110 & 0 \\
\hline 2 & $59 / \mathrm{F}$ & 19 & 0 & REST & 0 & + & 2 & 54 & 900 & 0 \\
\hline 3 & $58 / \mathrm{F}$ & 10 & 0 & CREST & 0 & 0 & 2 & 108 & ND & 0 \\
\hline 4 & $69 / F$ & 11 & 0 & CREST & + & 0 & 3 & 26 & 200 & + \\
\hline 5 & $50 / \mathrm{F}$ & 19 & 0 & CREST & + & 0 & 1 & 48 & 5 & 0 \\
\hline 6 & $49 / \mathrm{F}$ & 13 & 0 & CREST & + & 0 & 2 & ND & 110 & 0 \\
\hline 7 & $49 / \mathrm{F}$ & 2 & 0 & REST & 0 & + & 1 & 95 & 41 & 0 \\
\hline 8 & $48 / F$ & 25 & 0 & CREST & 0 & 0 & 2 & 73 & 170 & + \\
\hline 9 & $50 / \mathrm{M}$ & 1 & 0 & CREST & + & 0 & 2 & 61 & 56 & + \\
\hline 10 & $28 / F$ & 2 & 0 & CRET & 0 & 0 & 3 & 98 & 75 & 0 \\
\hline 11 & $41 / \mathrm{F}$ & 10 & 0 & RST & 0 & + & 3 & 163 & 34 & 0 \\
\hline 12 & $52 / \mathrm{F}$ & 10 & 0 & CRST & 0 & + & 1 & 68 & 34 & 0 \\
\hline 13 & $56 / \mathrm{F}$ & 27 & 0 & REST & + & 0 & 2 & 34 & 37 & + \\
\hline 14 & $24 / F$ & 2 & 0 & CRE & 0 & + & 0 & 93 & ND & 0 \\
\hline 15 & $50 / \mathrm{F}$ & 11 & 0 & CREST & 0 & 0 & 2 & 136 & 80 & + \\
\hline 16 & $58 / \mathrm{F}$ & 3 & 0 & REST & 0 & 0 & 1 & 70 & 80 & 0 \\
\hline 17 & $46 / F$ & 8 & 0 & RES & + & + & & 87 & 149 & + \\
\hline Mean & $49 \cdot 5$ & $12 \cdot 0$ & 0 & & $7 / 17^{*}$ & $7 / 17^{*}$ & 1.9 & 78.9 & $138 \cdot 7$ & $6 / 17^{*}$ \\
\hline SD & $10 \cdot 9$ & $9 \cdot 3$ & & & & & 0.9 & $36 \cdot 4$ & $217 \cdot 7$ & \\
\hline \multicolumn{11}{|l|}{ PSS } \\
\hline 3 & $56 / \mathrm{F}$ & 28 & + & CREST & 0 & 0 & 11 & 68 & 80 & ND \\
\hline 2 & $51 / F$ & 20 & + & $\mathrm{S}$ & 0 & + & 4 & 108 & 75 & 0 \\
\hline 6 & $51 / F$ & 6 & + & RES & 0 & + & 17 & 44 & 110 & 0 \\
\hline 11 & $69 / \mathrm{F}$ & 12 & + & CREST & + & + & 7 & 84 & 150 & + \\
\hline 7 & $49 / \mathrm{F}$ & 17 & + & CREST & 0 & 0 & 5 & 25 & 293 & 0 \\
\hline 4 & $51 / \mathrm{F}$ & 11 & + & $\mathrm{ES}$ & 0 & + & 7 & 46 & 500 & 0 \\
\hline 13 & $43 / F$ & 3 & + & CREST & + & + & 4 & 126 & 90 & 0 \\
\hline 8 & $46 / F$ & 27 & + & REST & 0 & + & 5 & 52 & 190 & 0 \\
\hline 16 & $46 / \mathrm{M}$ & 1 & + & CRES & 0 & 0 & 22 & 72 & 77 & 0 \\
\hline 17 & $24 / F$ & 5 & + & CREST & + & 0 & 17 & 210 & 690 & ND \\
\hline 1 & $50 / \mathrm{F}$ & 9 & + & CREST & + & 0 & 6 & 60 & 110 & 0 \\
\hline 9 & $58 / \mathrm{F}$ & 3 & + & RES & 0 & + & 19 & 96 & 150 & 0 \\
\hline 14 & $51 / \mathrm{F}$ & 26 & + & CREST & + & 0 & 4 & 57 & 160 & + \\
\hline 12 & $23 / F$ & 2 & + & $\mathrm{S}$ & 0 & 0 & 8 & 89 & 160 & 0 \\
\hline 15 & $50 / \mathrm{F}$ & 12 & + & CREST & + & + & 7 & 96 & 70 & 0 \\
\hline 5 & $52 / \mathrm{F}$ & 3 & + & CRES & + & 0 & 3 & 70 & 110 & 0 \\
\hline 10 & $49 / F$ & 6 & + & RES & + & + & 11 & 67 & 90 & 0 \\
\hline Mean & $48 \cdot 2$ & $11 \cdot 2$ & $17 / 17^{*}$ & & $8 / 17^{*}$ & $9 / 17^{*}$ & $9 \cdot 2$ & $80 \cdot 6$ & $132 \cdot 6$ & $2 / 15^{*}$ \\
\hline SD & $10 \cdot 9$ & $9 \cdot 19$ & & & & & $5 \cdot 96$ & $41 \cdot 9$ & $168 \cdot 2$ & \\
\hline \multicolumn{7}{|c|}{$\begin{array}{l}+=\text { present or positive. } \\
0=\text { negative or not there. } \\
{ }^{*}=\text { number positive/number tested. } \\
\mathrm{ND}=\text { not done. } \\
\mathrm{MI}=\text { myocardial infarction. }\end{array}$} & \multicolumn{4}{|c|}{$\begin{array}{l}\text { LAD = left axis deviation. } \\
\text { RAD = right axis deviation. } \\
\text { LVH = left ventricular hypertrophy. } \\
\text { WNL= within normal limits. } \\
\text { RVH=right ventricular hypertrophy. }\end{array}$} \\
\hline
\end{tabular}

were no differences between matched CREST and PSS patients except perhaps with respect to scleroderma myopathy, where a borderline difference was found.

Table 3 displays the mean degrees of organ involvement determined from the formulae in Appendix A. It also shows the standard deviations of the means, any statistical differences between the PSS and CREST groups, and the power of the calculation when no differences were found. Skin 

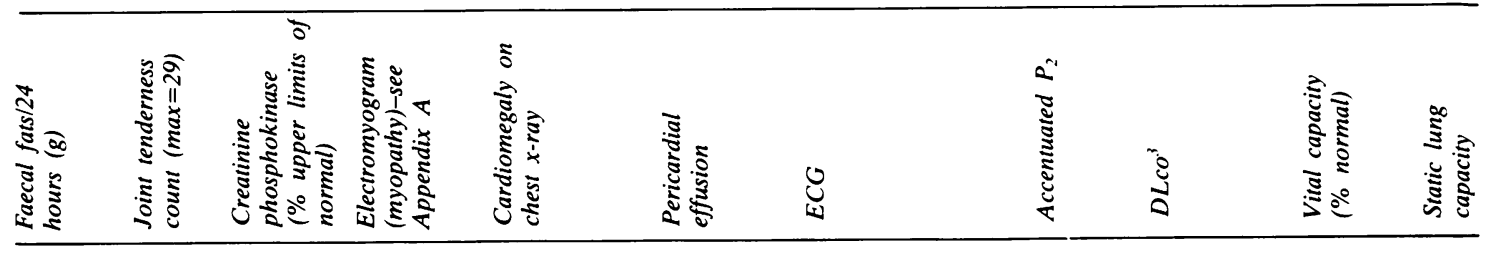

$\begin{array}{lrrl}7 \cdot 7 & 4 & 108 & + \\ 3 \cdot 9 & 7 & 49 & 0 \\ 16 & 12 & 38 & + \\ 8 \cdot 9 & 0 & 69 & 0 \\ 5 \cdot 1 & 2 & 60 & 0 \\ 5 \cdot 7 & 1 & 67 & + \\ 4 \cdot 4 & 12 & 90 & + \\ 11 & 21 & 36 & + \\ 18 & 1 & 53 & 0 \\ 1 \cdot 5 & 17 & 470 & + \\ 11 & 13 & 46 & 0 \\ 3 \cdot 7 & 17 & 52 & 0 \\ 25 & 4 & 44 & 0 \\ 5 \cdot 0 & 2 & 220 & + \\ 7 \cdot 5 & 2 & 78 & 0 \\ 1 \cdot 9 & 18 & 131 & 0 \\ \text { ND } & \text { ND } & \text { ND } & \text { ND }\end{array}$

+
0
0
+
0
0
+
0
0
0
0
0
0
0
0
+
+

$\begin{array}{ll}+ & \text { MI } \\ 0 & \text { LAD, LVH } \\ 0 & \text { WNL } \\ + & \text { RVH } \\ 0 & \text { WNL } \\ + & \text { WNL } \\ 0 & \text { RBBB, RVH, MI } \\ 0 & \text { WNL } \\ 0 & \text { WNL } \\ 0 & \text { WNL } \\ 0 & \text { WNL } \\ 0 & \text { RBBB } \\ 0 & \text { WNL } \\ \text { ND } & \text { WNL } \\ 0 & \text { WNL } \\ 0 & \text { MI } \\ 0 & \text { WNL }\end{array}$

$\begin{array}{lrrl}0 & 44 & 93 & 0 \cdot 12 \\ 0 & 67 & 64 & 0 \cdot 07 \\ 0 & 84 & 77 & 0 \cdot 10 \\ 0 & 20 & 90 & 0 \cdot 16 \\ 0 & 77 & 91 & 0 \cdot 19 \\ + & 97 & 98 & 0 \cdot 12 \\ 0 & 58 & 80 & 0 \cdot 28 \\ 0 & 58 & 115 & 0 \cdot 15 \\ 0 & 66 & 68 & 0 \cdot 05 \\ + & 92 & 98 & 0 \cdot 21 \\ 0 & 110 & 97 & 0 \cdot 16 \\ 0 & 56 & 116 & 0 \cdot 11 \\ 0 & 93 & 102 & \text { ND } \\ + & 64 & 41 & 0 \cdot 06 \\ 0 & 58 & 86 & 0 \cdot 20 \\ 0 & 72 & 62 & 0 \cdot 10 \\ 0 & 49 & 34 & \text { ND } \\ & & & \\ 3 / 17^{*} & 68 \cdot 5 & 83 & 0 \cdot 16 \\ & 22 \cdot 2 & 23 & 0 \cdot 07\end{array}$

\begin{tabular}{|c|c|c|c|c|c|c|c|c|c|c|}
\hline $19 \cdot 0$ & 26 & 29 & + & + & 0 & PVC & 0 & 54 & 120 & $0 \cdot 22$ \\
\hline $3 \cdot 4$ & 6 & 85 & + & + & 0 & WNL & 0 & 133 & 68 & $0 \cdot 12$ \\
\hline $9 \cdot 5$ & 25 & 55 & + & + & + & LVH, MI, IVCD & + & 78 & 80 & $0 \cdot 13$ \\
\hline 12 & 12 & 78 & + & 0 & 0 & WNL & 0 & 66 & 94 & $0 \cdot 04$ \\
\hline $5 \cdot 2$ & 0 & 54 & + & 0 & 0 & WNL & 0 & 77 & 73 & $0 \cdot 24$ \\
\hline 18 & 29 & 88 & 0 & + & 0 & RAD & 0 & 34 & 49 & $0 \cdot 16$ \\
\hline ND & 1 & 181 & ND & + & + & WNL & 0 & 48 & 47 & $0 \cdot 21$ \\
\hline $1 \cdot 2$ & 8 & 41 & + & 0 & 0 & WNL & 0 & 78 & 130 & $0 \cdot 19$ \\
\hline $4 \cdot 7$ & 17 & 46 & + & 0 & 0 & WNL & 0 & 95 & 53 & $0 \cdot 13$ \\
\hline ND & 7 & 125 & ND & 0 & ND & WNL & 0 & 94 & 64 & $0 \cdot 11$ \\
\hline 0.5 & 0 & 20 & 0 & 0 & 0 & WNL & 0 & 48 & 105 & $0 \cdot 15$ \\
\hline 10 & 10 & 515 & + & + & + & WNL & 0 & 57 & 82 & $0 \cdot 10$ \\
\hline $6 \cdot 5$ & 11 & 60 & + & 0 & 0 & WNL & 0 & 70 & 97 & $0 \cdot 03$ \\
\hline $1 \cdot 3$ & 6 & 196 & ND & 0 & 0 & LAD, MI & 0 & 64 & 56 & $0 \cdot 21$ \\
\hline $2 \cdot 4$ & 14 & 14 & + & 0 & 0 & WNL & 0 & 61 & 88 & $0 \cdot 28$ \\
\hline $5 \cdot 5$ & 25 & 69 & + & 0 & 0 & WNL & 0 & 90 & 117 & $0 \cdot 08$ \\
\hline $4 \cdot 7$ & 0 & 123 & 0 & 0 & + & WNL & 0 & 62 & 78 & $0 \cdot 08$ \\
\hline $6 \cdot 9$ & $11 \cdot 6$ & $104 \cdot 6$ & $11 / 14^{*}$ & $6 / 17$ & $4 / 16^{*}$ & & $1 / 17^{*}$ & $71 \cdot 1$ & 82 & $0 \cdot 14$ \\
\hline $5 \cdot 75$ & 9.7 & $117 \cdot 7$ & & & & & & $23 \cdot 2$ & 25 & $0 \cdot 06$ \\
\hline
\end{tabular}

$\mathrm{RBBB}=$ right bundle branch block.

$\mathrm{PVC}=$ premature ventricular contractions. IVCD =intraventricular conduction defect. $3=$ diffusing capacity.

$4=$ normal $\leqslant 150 \mathrm{mg} / 24$ hours.
$\mathrm{C}=$ Calcinosis.

$\mathbf{R}=$ Raynaud's phenomenon. $\mathrm{E}=$ Oesophageal dysmotility. $\mathrm{S}=$ Sclerodactyly.

$\mathrm{T}=$ Telangiectasia. involvement was different by definition $(\mathrm{p}<0 \cdot 001)$. The tendency for a difference in the presence of muscular involvement between the two groups $(p<0.06)$ was supported by the degree analysis (Appendix A), which showed that the PSS patients had more severe myopathy than the CREST group $(\mathrm{p}<0 \cdot 05)$. Further, non-smoking PSS patients had more severe pulmonary involvement than their CREST syndrome counterparts $(p<0.05)$; in contrast, smoking PSS and CREST patients did not 
Table 2 Matching of CREST and PSS patients for presence of organ involvement

\begin{tabular}{|c|c|c|c|c|c|}
\hline \multirow[t]{2}{*}{ Organ system } & \multicolumn{2}{|c|}{ Concordant pairs ${ }^{\dagger}$} & \multicolumn{3}{|c|}{ Non-concordant pairst } \\
\hline & $\begin{array}{l}+ \text { CREST } \\
+P S S\end{array}$ & $\begin{array}{l}-C R E S T \\
-P S S\end{array}$ & $\begin{array}{l}+ \text { CREST } \\
-P S S\end{array}$ & $\begin{array}{l}-C R E S T \\
+P S S\end{array}$ & $p^{*}$ \\
\hline Skin & 17 & 0 & 0) & 0 & - \\
\hline Pulmonary & 12 & 0 & 2 & 3 & - \\
\hline General Cardiac & 8 & 3 & 3 & 3 & - \\
\hline Left Heart & () & 11 & 4 & 2 & - \\
\hline Right Heart & 1 & 11 & 5 & 0 & - \\
\hline Renal & 4 & 7 & 1 & 5 & - \\
\hline Skeletal & 17 & 0 & () & ) & - \\
\hline Muscular & 8 & 1 & 1 & 6 & 0.06 \\
\hline Upper GI & 13 & 0 & 2 & 2 & - \\
\hline Lower GI & 8 & 4 & 2 & 3 & - \\
\hline
\end{tabular}

*Based on Fisher's exact test and corrected for repeated measurements.

†Refers to the matching of patient pairs for presence or absence of organ involvement from Appendix A (c.g., for pulmonary involvement. 12 pairs of patients were concordant for presence or absence of pulmonary disease, two sets of patients were seen where the CREST patients had pulmonary disease. and the PSS patient did not and three sets were seen which were vice versa).

Table 3 Comparisons of degrees of organ involvement

\begin{tabular}{|c|c|c|c|c|c|c|c|c|}
\hline & \multicolumn{3}{|c|}{ CREST } & \multicolumn{3}{|c|}{ PSS } & \multirow[t]{2}{*}{$P$} & \multirow[t]{2}{*}{ Power } \\
\hline & $N$ & Mean & $S D^{*}$ & $N$ & Mean & $S D^{*}$ & & \\
\hline Integument & 17 & 6.7 & $3 \cdot 7$ & 17 & $16 \cdot 4$ & $5 \cdot 5$ & 0.001 & - \\
\hline Skeletal & 17 & 11.9 & $3 \cdot 7$ & 17 & $16 \cdot 3$ & $10 \cdot 7$ & $0 \cdot 20$ & 0.7 \\
\hline Muscular & 13 & 1.9 & 1.9 & 13 & $4 \cdot 3$ & $2 \cdot 1$ & 0.02 & - \\
\hline General Cardiac & 17 & $2 \cdot 1$ & $2 \cdot 4$ & 17 & $2 \cdot 0$ & $2 \cdot 6$ & 0.9 & $0 \cdot 1$ \\
\hline Left Heart & 17 & 0.4 & $0 \cdot 8$ & 17 & $0 \cdot 6$ & 1.7 & 0.6 & $0 \cdot 3$ \\
\hline Right Heart & 17 & 0.8 & $1 \cdot 2$ & 17 & $0 \cdot 2$ & 0.7 & 0.3 & 0.5 \\
\hline \multicolumn{9}{|l|}{ Pulmonary: } \\
\hline Smokers & 7 & $8 \cdot 3$ & $3 \cdot 3$ & 3 & 7.9 & $2 \cdot 9$ & $(0.80$ & $0 \cdot 1$ \\
\hline Non-Smokers & 10 & $5 \cdot 2$ & $3 \cdot 2$ & 14 & $6 \cdot 7$ & 3.7 & (0.04 & - \\
\hline Renal & 17 & $2 \cdot 5$ & $1 \cdot 7$ & 17 & $4 \cdot 0$ & $3 \cdot 4$ & $0 \cdot 1$ & 0.5 \\
\hline Upper GI & 17 & $3 \cdot 5$ & $1 \cdot 7$ & 17 & 3.4 & $1 \cdot 5$ & 0.8 & 0.9 \\
\hline Lower GI & 16 & $3 \cdot 1$ & $3 \cdot 3$ & 16 & $2 \cdot 7$ & $2 \cdot 7$ & 0.7 & $0 \cdot 1$ \\
\hline
\end{tabular}

The degree of organ involvement was determined as formulated in Appendix A. Means were tested for statistical differences by Student's paired $t$ test in all cases except pulmonary involvement, where Student's unpaired $t$ test was used.

* Standard deviation.

have differing degrees of pulmonary disease. No other organ system was different in this comparison.

Table 4 displays the serological variables that were measured. As can be seen, there were usually no differences between the two groups. Latex fixation and ANA were positive in a high percentage in both groups and even anti-single stranded-DNA was abnormal in $15 \%$ of the cases. There were no instances of decreased $\mathrm{C} 3$ and no differences between the two groups in immunoglobulin $\mathbf{G}, \mathbf{M}$, or A concentrations. In fact, only anti-RNP was different in our comparisons $(p<0.04)$.

Although none of the PSS patients were RNP positive, five of the 17 CREST patients had antiRNP in their serum. All titres were greater than 1:2048, by haemagglutination. These five RNP
Table 4 CREST vs. PSS serologies

\begin{tabular}{lllll}
\hline & \multicolumn{2}{l}{ CREST } & \multicolumn{2}{l}{ PSS } \\
\cline { 2 - 3 } & \multicolumn{2}{l}{$\begin{array}{l}\text { No. positivel } \\
\text { No. done }\end{array}$} & $\%$ & \multicolumn{2}{l}{$\begin{array}{l}\text { No. positivel } \\
\text { No. done }\end{array}$} & $\%$ \\
\hline Latex $(>1: 40)$ & $9 / 17$ & 53 & $11 / 17$ & 65 \\
Titre $(\geqslant 1: 160)$ & $4 / 17$ & 24 & $3 / 17$ & 18 \\
ANA $(\geqslant 1: 20) \dagger$ & $9 / 16$ & 56 & $14 / 17$ & 82 \\
$\begin{array}{c}\text { Anti-ss-DNA } \\
(>20 \%) \ddagger\end{array}$ & $1 / 16$ & 6 & $4 / 17$ & 24 \\
$\begin{array}{c}\text { Anti-RNP } \\
(>1: 1256) \S\end{array}$ & $5 / 12^{*}$ & 42 & $0 / 13$ & 0 \\
\hline
\end{tabular}

${ }^{*} \mathrm{p}<0.04$

No differences in IgA, IgM, IgG, or C3.

†Antinuclear antibody using rat-liver as substrate.

$\ddagger$ Anti-single-stranded DNA antibody.

$\S A n t i-$ ribonucleoprotein antibody. 
positive CREST patients did not meet criteria for any other rheumatological disease. As expected, their ANA were positive (titres 1:640 to greater than 1:10 240). Rheumatoid factor was negative in two and anti-ss DNA was not raised in any. There were no erosions on $x$-ray, rashes, or myositis. Pulmonary hypertension was noted by right heart catheterisation in two out of these five patients and accentuated $\mathrm{P} 2$, pulmonary fibrosis, and/or decreased diffusing capacity was found in three patients (including the above two with pulmonary hypertension). Renal disease was found in one patient (creatinine clearance $54 \mathrm{ml} / \mathrm{min} ; 24 \mathrm{~h}$ urine protein $900 \mathrm{mg} / 24 \mathrm{~h}$ ) and gastrointestinal involvement (oesophageal stricture and duodenal dilatation) was found in two patients. The RNP positive CREST patients did not differ statistically from the RNP negative patients with respect to the degree or presence of organ involvement or in other serological abnormalities. The 12 CREST patients with minor criteria for PSS were also not different clinically or serologically from the five CREST patients who did not have PSS by any criteria.

\section{Discussion}

Although the CREST syndrome was first described in 1911 and again described in 1964, it was only in 1973 that oesophageal involvement was added to it. ${ }^{-11}$ The CREST syndrome is sometimes considered a more benign variant of PSS, ${ }^{2-4}$ but other authors emphasise that visceral involvement, including pulmonary hypertension, can occur. ${ }^{56}$ In a previously published report comparing CREST syndrome with PSS the CREST patients frequently had acrosclerosis; thus they had PSS by the major ARA criterion. ${ }^{7}$ Our study specifically excluded any patients from the CREST group who had hide-bound, sclerotic skin proximal to the MCPs, while all PSS patients met this major criterion. The PSS group was matched to the CREST patients with respect to age, sex, and, most importantly, duration of disease from first symptom.

The only clear difference with respect to the presence of organ involvement was myopathy (see Appendix A), where more PSS patients had myopathy than did CREST patients.

When examining the degree of organ involvement, skin involvement was different (by definition), and muscular involvement was again greater in the PSS group.

Shortness of breath, fibrosis on chest $x$-ray, diffusing capacity (DLCo), forced expiratory volume in one second $\left(\mathrm{FEV}_{1}\right)$, forced vital capacity (FVC), total lung capacity (TLC) and compliance were all determined during pulmonary testing. Shortness of breath and fibrosis were included in the pulmonary evaluation, and given increased weights, because they are clinically important (Appendix A). The five measured pulmonary functions are not necessarily independent estimates, so various measurement combinations were tested to ascertain if such combinations altered the results. In accordance with previous reports the diffusing capacity was found to be a sensitive indicator of pulmonary disease. ${ }^{12}$ Since many combinations of measurement (e.g., $\mathrm{FEV}_{1}+\mathrm{TLC}+$ DLco + compliance; DLco + TLC, DLco + FEV 1 , etc.) were examined but did not change the results, the DLco was the single pulmonary function test used for the pulmonary evaluation. With shortness of breath and fibrosis on chest $x$-ray it made up the elements used to define the degree of pulmonary involvement (see Appendix A). Non-smoking PSS patients had more severe pulmonary disease than their non-smoking CREST syndrome counterparts $(p<0 \cdot 05)$. Smoking made both groups' lung disease worse but obscured the differences between groups, for no differences in pulmonary involvement were found when the smokers in each group were compared.

No other differences were found for the seven other systems tested (upper gastrointestinal, lower GI, general cardiac, left heart, right heart, skeletal, and renal). When no statistical differences are found, power calculations estimate the assurance that false negatives did not occur. High power estimates ensure against false negatives. On the other hand low power estimates sometimes mean that large numbers of patients are needed because differences between patient groups are small (i.e., if we need large numbers of patients to achieve a given power, then the differences between patient groups are probably quite small, given reasonable standard deviations).

In our study the power estimates were high for skeletal and upper GI involvement, thus ensuring against false negatives. However, power estimates were modest for other organ systems tested. When we calculated the number of patients needed to achieve $80 \%$ assurance against a false negative (power $=0.8$ ) for the latter organs, we found that at least 66 matched patients were required for lower GI and right heart evaluations; 90-110 matched patients were needed for renal and left heart involvement; and over 3100 patients were required for general cardiac and pulmonary evaluations (smokers only). With such large populations needed to satisfy power requirements, we concluded that, in most of the latter categories, any potential differences were probably quite small and not prognostically significant for an individual patient.

Disease duration was calculated from the patient's 
first symptom, not from the date of diagnosis. Thus our patients' disease appeared to be of longer standing than if we had chosen the date of diagnosis for the 'beginning' of their disease. While we prospectively followed up over 150 patients with systemic sclerosis or its variations, only 17 had CREST by our definition and only five had their disease for less than five years (Table 1). Perhaps this is because, as a tertiary care facility, we do not see patients with early disease. Thus the mean disease duration from first symptom in our CREST patients was 12 years. The five CREST patients with disease duration of less than five years had visceral involvement comparable to the CREST patients with longer-standing disease. Had we been able to compare patients with very early disease, the results might have been slightly different, but this comparison was not possible. In addition, because the survival rate of PSS patients has been reported to be only $45 \%,{ }^{13}$ whereas it is still possible that survival of CREST patients may be somewhat better, the survivors who were available for enrolment in our study (a mean of 12 years after first symptoms) may represent a subgroup who did not develop early lethal organ system involvement.

In this population of patients anti-RNP was not a particularly reliable prognostic sign, as the anti-RNP positive CREST patients were not different from the anti-RNP negative CREST patients. No PSS patients were anti-RNP positive. It should be emphasised that none of the anti-RNP positive patients met criteria for any other rheumatic disease.

In summary, our CREST patients without the skin involvement proximal to the MCPs have cardiac, renal, skeletal, and gastrointestinal morbidity that is not very different from that of carefully matched PSS patients. Even if there are differences in any of the above systems, those differences are not large enough to be prognostically significant. Pulmonary involvement, at least for non-smokers, is less in CREST syndrome patients. The PSS patients, on the other hand, have more muscular involvement than the matched CREST patients. No serological differences, except for anti-RNP, were noted between the two populations.

We gratefully acknowledge Dana Brown for her technical assistance, and Evelyn Tackels and Sue Debe for their secretarial help without which this study could not have been completed.

This work was supported in part by the Palo Alto Junior Womens Club and CRC Grant, No. USPHS RR 00865.

\section{Appendix A}

Skin evaluation

A. Taut hidebound skin of the fingers and proximal to the MCPs. ${ }^{*}$ B. Sclerodactyly.*
C. Subcutaneous calcinosis. ${ }^{*}$

D. Ulcers of skin and/or fingers.*

E. Digital pitting scars. ${ }^{*}$

G. Skin index (0-30) - see text.

Involvement is present if $3(\mathrm{~A}+\mathrm{B})+\mathrm{C}+\mathrm{D}+\mathrm{E}+\mathrm{F} \geqslant 6$.

Degree of involvement is defined by 2(D) $+\mathrm{C}+\mathrm{D}+\mathrm{G}=$

Pulmonary evaluation

Involvement is present if patient has shortness of breath, rales, or fibrosis, has diffusing capacity less than $70 \%$ of predicted, or has lung compliance less than $0 \cdot 15$.

Degree of involvement is defined as follows (smokers and non-smokers are analysed separately):

$$
1 \cdot 5\left(\mathrm{SOB}^{*}\right)+3\left(\text { fibrosis }^{*}\right)+\frac{2}{\text { Diffusing Capacity }}{ }^{1}
$$

Skeletal evaluation

A. Joint count $^{2}(0-29)$.

B. Erosive joint disease on $x$-ray. ${ }^{*}$

C. Hand or joint $x$-ray positive for PSS. ${ }^{3}$

Involvement is present if patient has tender joints, erosive joint disease on $x$-ray, or $x$-ray changes of PSS; as defined above.

Degree of involvement is defined by $A+2 \cdot 5(B)+2 \cdot 5(C)=$

$$
\overline{\max =34}
$$

Muscular evaluation

A. $\mathrm{CPK}^{4}$

B. EMG.

Involvement is present if: $\mathrm{CPK}^{4}+\mathrm{EMG}^{5} \geqslant 2$

Degree of involvement is defined by $\mathrm{CPK}^{4}+2\left(\mathrm{EMG}^{5}\right)=$

Upper GI evaluation

A. Cine-oesophagram positive for typical PSS changes.*

B. Oesophageal structure. ${ }^{*}$

C. Dysphagia.*

Involvement is present if the patient has any of the above.

Degree of involvement is defined by $\mathrm{A}+\mathrm{B}+\mathrm{C}=$

$$
\max =6
$$

Lower GI evaluation

A. Colonic pseudosacculations.*

B. Faecal fat. ${ }^{6}$

C. Duodenal dilatations. ${ }^{*}$

Involvement is present if the patient has any of the above, including abnormal faecal fat determination.

Degree of involvement is defined by $2(\mathrm{~A})+\mathrm{B}+\mathrm{C}$

$$
\overline{\max }=9
$$

General cardiac evaluation

A. Abnormal ECG defined by any of the findings listed under left or right evaluation below.*

B. Pericardial evaluation on echocardiogram.*

C. Treadmill showing ischaemia or significant arrhythmia. ${ }^{7 *}$

D. Cardiomegaly on chest $x$-ray.

Involvement is present if the patient has any of the above.

Degree of involvement is defined by $\mathrm{A}+\mathrm{B}+\mathrm{C}+\mathrm{D}=$

Right heart evaluation

$$
\overline{\max =8} \text {. }
$$

A. Accentuated second pulmonary sound on physical examination. ${ }^{*}$

B. Right ventricular hypertrophy (RVH), right axis deviation (RAD), or right atrial enlargement (RAE) on ECG.*

C. Right bundle branch block (RBBB) on ECG.*

Involvement is present if the patient has any of the above.

Degree of involvement is defined by $\mathrm{A}+\mathrm{B}+\mathrm{C}=$ $\overline{\max =6}$ 
Left heart evaluation

A. Left ventricular hypertrophy (LVH), left axis deviation (LAD). or left atrial enlargement (LAE) on ECG. ${ }^{*}$

B. Left bundle branch block (LBBB) on ECG.*

C. Intraventricular conduction delay on ECG. ${ }^{*}$

D. Myocardial infarction by history on ECG.*

Involvement is present if the patient has any of the above.

Degree of involvement is defined by $\mathrm{A}+\mathrm{B}+\mathrm{C}+\mathrm{D}=$

Renal evaluation

A. Scleroderma renal crises. $^{*}$

B. Proteinuria.

C. Creatinine clearance less than $66 \mathrm{ml} / \mathrm{min}$.

D. Urine protein $(\mathrm{mg} / 24$ hours).

E. Creatinine clearance $(\mathrm{ml} / \mathrm{min})$.

Involvement is present if patient has (or has had) scleroderma renal crises, abnormal proteinuria, or abnormally low creatinine clearance.

Degree of involvement is defined by

$$
5(\mathrm{~A})+\frac{\mathrm{D}}{150}+\frac{100}{\mathrm{E}}=\overline{\max =150} \text {. }
$$

${ }^{*} 0=$ no or none; $2=$ yes or present.

'As percent of normal, expressed as a decimal.

${ }^{2}$ Considered positive if tender to firm palpation or painful on motion.

${ }^{3}$ Typical changes of sub-cutaneous calcinosis and acro-osteolysis $0=$ no; $2=$ yes.

${ }^{4}$ Percent of normal, expressed as a decimal.

${ }^{5} 0=$ normal; $2=$ polyphasic potentials of normal amplitude without positive sharp waves or insertional irritability; no patient exhibited the EMG seen in inflammatory myositis (i.e., sharp waves \pm insertional irritability).

${ }^{6} 0=<10 \mathrm{~g}$ faecal fat $/ 24$ hours; $2=>10$ to $20 \mathrm{~g}$ faecal fat $/ 24$ hours; $3=>20 \mathrm{~g}$ faecal fat $/ 24$ hours - all on a $100 \mathrm{~g}$ fat diet.

${ }^{7}>5 \mathrm{PVCs} / \mathrm{min}$, frequent PACs, aberrent conduction, supraventricular or ventricular tachy arrhythmias.

${ }^{8} 0=\leqslant 150 \mathrm{mg}$ protein $/ 24$ hour urine collection; $2=>150 \mathrm{mg}$ protein/24 hour urine collection.

\section{References}

1 Subcommittee for Scleroderma Criteria of the ARA Diagnostic and Therapeutic Criteria Committee. Preliminary criteria for the classification of systemic sclerosis (scleroderma). Arthritis Rheum 1980; 23: 581-90.

2 Carr R D, Eldred H B, Stevenson T D. CREST syndrome. Arch Dermatol 1965; 92: 519-25.

3 Rodnan G P. Medsger T A. Jr, Buckingham R B. Progressive systemic sclerosis-CREST syndrome: observations on natural history and late complications in 90 patients. Arthritis Rheum 1975; 18: 423.

4 Fritzler M J, Kinsella T D, Garbritt E. The CREST syndrome: a distinct serologic entity with anti-centromere antibodies. $\mathrm{Am} \mathrm{J}$ Med 1980; 69: 520-6.

5 Salerni R, Rodnan G P, Loon D F. Shaver J A. Pulmonary hypertension in the CREST syndrome variant of progressive systemic sclerosis (scleroderma). Ann Intern Med 1977; 86: $394-9$.

6 Trell E, Lindstrom C. Pulmonary hypertension in systemic sclerosis. Ann Rheum Dis 1971; 30: 390-3.

7 Velayos E E. Masi A T. Stevens M B, Shulman L E. The CREST syndrome, comparison with systemic sclerosis (scleroderma). Arch Intern Med 1979; 139: 1240-4.

8 Cohen J. Statistical power analysis for the behavioral sciences. New York: Academic Press, 1969.

9 Thibierge G, Weissenbach R J. Concrétions calcaires souscutanées et sclérodermic. Ann Dermatol Venereol 1911: 42: 129-45.

10 Winterbauer R H. Multiple telangectasia, Raynaud's phenomenon, sclerodactyly and subcutaneous calcinosis: a syndrome mimicking hereditary hemorrhagic telangectasia. Johns Hopkins Med J 1964; 114: 361-8.

11 Frayha R A. Scarola J A. Shulman L E. Calcinosis in scleroderma: a re-evaluation of the CRST syndrome. Arthritis Rheum 1973; 16: 542-52.

12 Ungerer R G, Tashkin D P, Furst D E, Clements P J, et al. Prevalence and clinical correlates of pulmonary hypertension in progressive systemic sclerosis. Am J Med 1983; 75: 65-74.

13 Rodnan G P. Progressive systemic sclerosis (scleroderma). In: McCarty D H. ed. Arthritis and allied conditions. 9th ed. Philadelphia: Lea and Febiger, 1979: 762-809. 